\title{
Adenoid Cystic Carcinoma of Parotid Salivary Gland-A Case Study
}

\author{
Shuaib Kayode Aremu \\ ENT Department, Federal Teaching Hospital Ido-Ekiti/Afe Babalola University, Ado-Ekiti, Nigeria \\ Email: shuaib.aremu@gmail.com
}

How to cite this paper: Aremu, S.K. (2018) Adenoid Cystic Carcinoma of Parotid Salivary Gland-A Case Study. Case Reports in Clinical Medicine, 7, 576-581. https://doi.org/10.4236/crcm.2018.711052

Received: October 22, 2018

Accepted: November 13, 2018

Published: November 16, 2018

Copyright $\odot 2018$ by author and Scientific Research Publishing Inc. This work is licensed under the Creative Commons Attribution International License (CC BY 4.0).

http://creativecommons.org/licenses/by/4.0/

\section{c) (i) Open Access}

\begin{abstract}
Adenoid Cystic Carcinoma (ACC) is an infrequent slow growing epithelial tumour constituting for around less than $1 \%$ of all the oral and maxillo-facial malignancies and almost $10 \%$ of all the salivary gland tumors. Parotid gland is the second most common site to be involved in the head and neck region along with submandibular gland, Palate being the most common site involved in the oral cavity. Key feature of these tumors include its asymptomatic presentation, indolent nature, typically showing infiltrative growth and peri-neural invasion. Herein, we report a case of adenoid cystic carcinoma of right parotid gland of a 33-year-old male who presented with complaint of painless slow enlargement of left parotid gland and facial muscle weakness. On Examination firm mass in the region of the left parotid gland as well as left facial paralysis was seen. Biopsy results and further management is discussed here within.
\end{abstract}

\section{Keywords}

Adenoid Cystic Carcinoma, Parotid Gland, Malignant Salivary Gland Tumor

\section{Introduction}

Adenoid cystic carcinoma (ACC) is a rare malignant tumor arising from salivary glands of head and neck region. This type of neoplasm was first elaborated by Billroth in 1856 as a benign neoplasm and was called cylindroma for cribriform like appearance made by tumor cells with cylindrical pseudo spaces [1]. About $10 \%-15 \%$ of salivary gland mass are ACCs [2]. ACC mostly occurs in minor salivary glands and submandibular gland and less often, in the sublingual and parotid glands [3] [4]. It is the most common malignant tumor of the minor salivary glands [5]. Further infrequent locations comprise the Respiratory tract, GI tract, lacrimal glands and adnexal dermal glands. Greatest ACC patients are 
in their fifth and sixth decade of their life and women are to some extent more affected than men [2] [3] [4]. ACC is a rare head and neck tumor. Considering the sites of ACC, palate is the commonest site. Fewer common sites where this tumor may be met are vulva [6], cervix [7], Cowper's glands in female reproductive tract [8], oesophagus [9], external auditory canal [10], middle ear [11] and nasopharynx [12]. Infrequently, it may also present as primary intraosseous mass of the mandible and maxilla [13].

Facial nerve restoration is mandatory in malignant mass of the parotid gland after radical parotidectomy $(\mathrm{RP})$.

\section{Case Report}

A 33 year-old man presented to a private ENT facility with history of painless gradual enlargement of the leftt parotid gland for one year and facial muscle weakness since one week (Figure 1). On examination a firm, fixed mass $3.5 \times 2.5$ $\mathrm{cm}$ in the parotid gland region was found with left lower motor facial (VII) nerve paralysis. There was a palpable left cervical lymph node which was fixed. His Vitals were within normal limits. Haematological investigations including Complete Blood Count (CBC), Erythrocyte Sedimentation Rate (ESR) and Biochemical investigations including Liver Function Test (LFT) and Renal Function Test (RFT) were in normal range.

Other possibilities of parotid swelling including granulomatous tuberculosis were ruled out.

Magnetic resonance imaging (MRI) showed an enlargement of the right parotid gland with evidence of multiple cystic masses including both the superficial and deep parts of the gland. Fine-needle aspiration (FNA) biopsy was used for diagnosis. Cyto-pathological examination suggested ACC with the discovery of big globules of the extracellular matrix, partly enclosed by basaloid tumour cells but missing characteristic globules.

A radical parotidectomy (Figure 2) and modified radical neck dissection with spinal accessory nerve preservation was planned under GA. Figure 3 Shows the

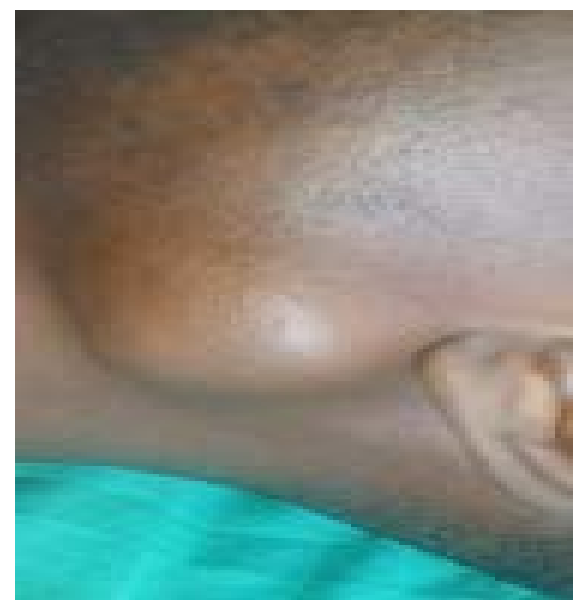

Figure 1. Left parotid Mass $3.5 \times 2.5 \mathrm{~cm}$. 


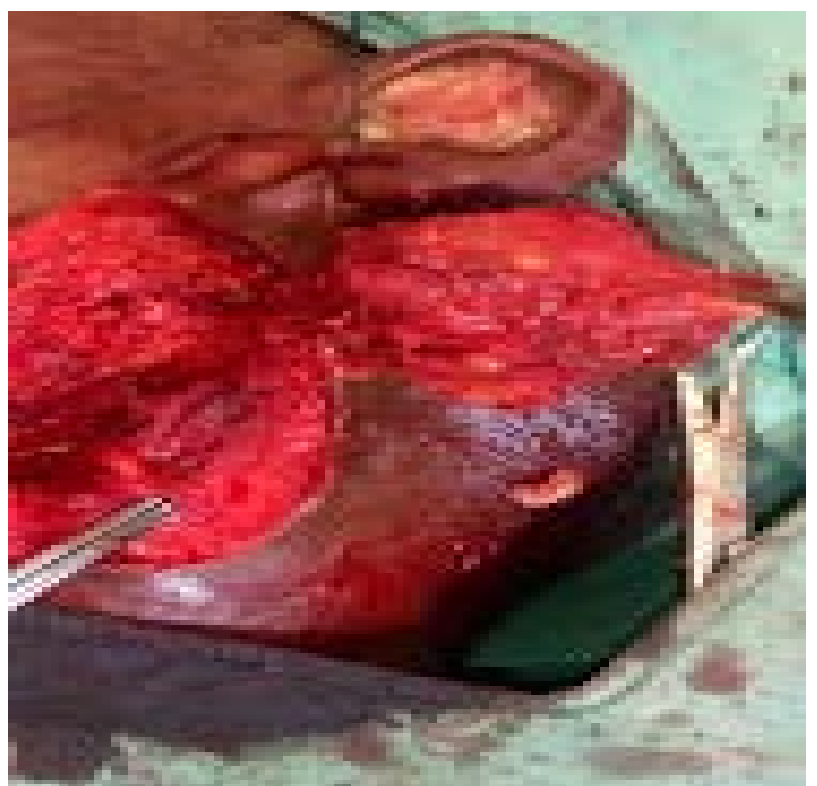

Figure 2. Left parotid mass almost dissected out.

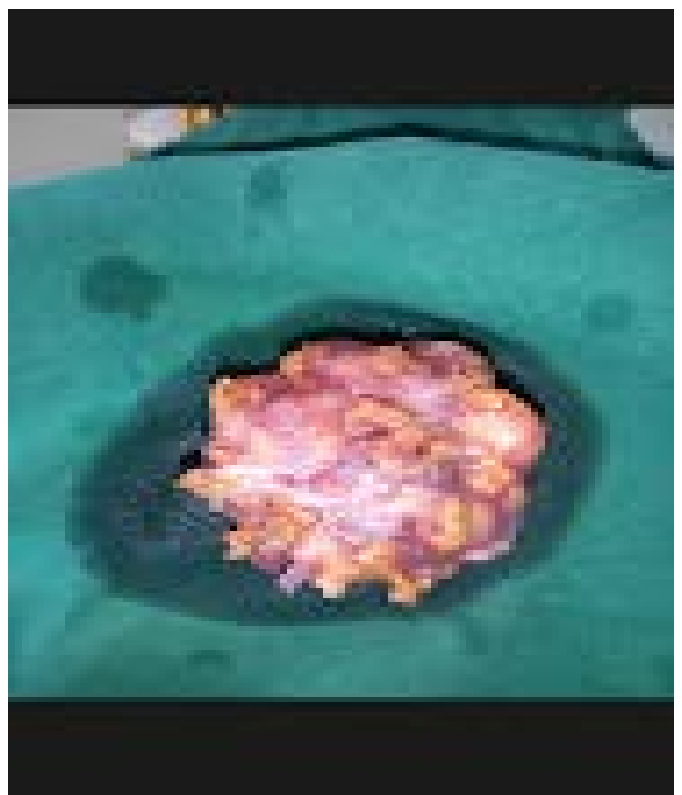

Figure 3. Excised Left parotid gland tissue.

mass excised. After resection of the parotid neoplasm, modified neck dissection was then added and the donor nerve graft was prepared from the great auricular nerve. Histological result showed features of adenocystic carcinoma of the parotid gland.

The post-op time was uneventful without any significant complications. Four weeks later, the patient was irradiated with 2 Gy radiations; the total dose was 60 Gy.

The patient was followed up every six month, and improvement in the facial asymmetry was noted. 


\section{Discussion}

Adenoid cystic carcinoma utmost often presents as a test owing to the uncommonness of the lesion. Most findings concerning ADCC are actually grounded upon studies with a minor number of patients and there is a necessity for further information about its clinical behaviour as well as treatment modalities and their consequences [14].

ACCs of the minor glands have been described to have poorer prognosis than those of the major salivary glands [15] [16]. Tumors linking the nose, paranasal sinuses and maxillary sinus have the worst prognosis as they are typically noticed with higher stages at the period of diagnosis [17].

The differential diagnosis of ACC comprises basal cell adenoma (BCA), mixed tumor and basaloid squamous cell carcinoma (BSC). The cribriform form so typical of ACC may also infrequently be seen in BCA, mixed tumor and PLGA, and the difference amongst PLGA and ACC is more perplexing. A polymorphous style characterizes PLGA whereas ACC has a more incomplete range of histologic patterns with no more than three patterns. Foci of papillary growth and areas of single cell infiltration are distinctive of PLGA. Basophilic pools of glycosaminoglycans are appreciated in ACC but not in PLGA. PLGA displays even cell population with cytologically bland, round or oval vesicular nuclei and pale eosinophilic cytoplasm while cells in ACC have clear cytoplasm, angular, hyperchromatic nuclei and may show mitotic activity. The Ki-67 index is stated to be 10 times advanced in ACC equated to PLGA. Smooth muscle markers of myoepithelial differentiation are positive in ACC but negative in PLGA [18]. Though PLGA may form solid spaces, they lack the overall high-grade texture as associated with ADCC.

In our patient, the ACC was found in the major salivary gland, the parotid gland and the patient presented late when there was already facial nerve palsy.

Most ACCs developing in major salivary glands are treated surgically, as done in this patient, with the likely addition of adjunctive radiotherapy [19]. The most likely indications for postoperative radiation in ACCs comprise advanced T-stage, positive microscopic tumormargins, cervical nodes metastases, solid histo-pathological characteristics, perineural invasion (most likely VII nerve), and recurring tumours [20]. Early presentation before nerve palsy is advised for patients with ACC of the parotid gland as this one of the determinants of good prognosis. These hostile predictive indicators increase the already high risk for locoregional relapse, distant metastases, or decreased survival rate that may benefit from the addition of postoperative radiation as part of an aggressive therapeutic regimen. Available reports of locoregional control for ACCs treated with surgery single-handedly range from $40.46 \%$ five years afterward the surgery [20].

\section{Conclusion}

ADCC is pretty a rare salivary gland malignancy. It is distinctive for its unusual 
histopathological topographies and tendency for perineural invasion. The primary treatment aim in ACC patients is local control, normal functionality and distant metastasis prevention. For this resolution, timely detection of the lesion is must, in order to allow a more constructive prognosis and healthier quality of life. Long-term follow-up of patient at regular intervals is mandatory.

\section{Consent}

Informed consent was obtained from the patient before writing this case report.

\section{Ethical Approval}

This was obtained from the ethical committee of our hospital before writing this case report.

\section{Conflicts of Interest}

The author declares no conflicts of interest regarding the publication of this paper.

\section{References}

[1] Szanto, P.A., Luna, M.A., Tortoledo, M.E. and White, R.A. (1984) Histologic Grading of Adenoid Cystic Carcinoma of the Salivary Glands. Cancer, 54, 1062-1069. https://doi.org/10.1002/1097-0142(19840915)54:6<1062::AID-CNCR2820540622>3. $0 . \mathrm{CO} ; 2-\mathrm{E}$

[2] Chummun, S., McLean, N.R., Kelly, C.G., Dawes, P.J., Meikle, D., Fellows, S., et al. (2001) Adenoid Cystic Carcinoma of the Head and Neck. British Journal of Plastic Surgery, 54, 476-480. https://doi.org/10.1054/bjps.2001.3636

[3] Nascimento, A.G., Amaral, A.L., Prado, L.A., Kligerman, J. and Silveira, T.R. (1986) Adenoid Cystic Carcinoma of Salivary Glands. A Study of 61 Cases with Clinicopathologic Correlation. Cancer, 57, 312-319.

https://doi.org/10.1002/1097-0142(19860115)57:2<312::AID-CNCR2820570220>3.0 .CO;2-A

[4] Mendenhall, W.M., Morris, C.G., Amdur, R.J., Werning J.W., Hinerman, R.W. and Villaret, D.B. (2004) Radiotherapy Alone or Combined with Surgery for Adenoid Cystic Carcinoma of the Head and Neck. Head Neck, 26, 154-162.

https://doi.org/10.1002/hed.10380

[5] Spiro, R.H., Huvos, A.G. and Strong, E.W. (1979) Adenoid Cystic Carcinoma: Factors Influencing Survival. The American Journal of Surgery, 138, 579-583. https://doi.org/10.1016/0002-9610(79)90423-9

[6] Abell, M.R. (1963) Adenocystic (Pseudoadenomatous) Basal Cell Carcinoma of Vestibular Glands of Vulva. American Journal of Obstetrics and Gynecology, 86, 470-482. https://doi.org/10.1016/0002-9378(63)90172-8

[7] Gallager, H.S., Simpson, C.B. and Ayala, A.G. (1971) Adenoid Cystic Carcinoma of the Uterine Cervix. Report of 4 Cases. Cancer, 27, 1398-1402.

https://doi.org/10.1002/1097-0142(197106)27:6<1398::AID-CNCR2820270620>3.0. CO;2-P

[8] Carpenter, A.A. and Bernardo Jr., J.R. (1971) Adenoid Cystic Carcinoma of Cowper's Glands: Case Report. The Journal of Urology, 106, 701-703. 
https://doi.org/10.1016/S0022-5347(17)61379-X

[9] Nelms, D.C. and Luna, M.A. (1972) Primary Adenoid Cystic Carcinoma (Cylindromatous Carcinoma) of the Oesophagus. Cancer, 29, 440-443.

https://doi.org/10.1002/1097-0142(197202)29:2<440::AID-CNCR2820290228>3.0.C $\underline{\mathrm{O} ; 2-\mathrm{V}}$

[10] Ramadass, T. (1966) Cylindroma of External Ear. The Journal of Laryngology \& Otology, 80, 863-866. https://doi.org/10.1017/S0022215100066093

[11] Baruah, T. (1977) Adenoid Cystic Carcinoma of Middle Ear. Indian Journal of Otolaryngology and Head \& Neck Surgery, 29, 143-144.

[12] Iqbal, M.S. and Gurmurthy, J. (1991) Adenoid Cystic Carcinoma of Nasopharynx. Indian Journal of Otolaryngology and Head \& Neck Surgery, 43, 199-200.

[13] Dhawan, I.K., Bhargava, S., Nayak, N.C. and Gupta, R.K. (1970) Central Salivary Gland Tumours of Jaws. Cancer, 26, 211-217.

https://doi.org/10.1002/1097-0142(197007)26:1<211::AID-CNCR2820260127>3.0.C $\underline{\mathrm{O} ; 2-\mathrm{O}}$

[14] Grahne, B., Lauren, C. and Holsti, L.R. (1977) Clinical and Histological Malignancy of Adenoid Cystic Carcinoma. The Journal of Laryngology \& Otology, 91, 743-749. https://doi.org/10.1017/S0022215100084310

[15] Kaur, A., Harrigan, M.R., MeKeever, P.E. and Ross, D.A. (1999) Adenoid Cystic Carcinoma Metastatic to the Dura: Report of Two Cases. Journal of Neuro-Oncology, 44, 267-273. https://doi.org/10.1023/A:1006352307507

[16] Dal Maso, M.D. and Lippi, L. (1985) Adenoid Cystic Carcinoma of the Head and Neck: A Clinical Study of 37 Cases. Laryngoscope, 95, 177-181.

https://doi.org/10.1288/00005537-198502000-00009

[17] Kokemueller, H., Eckardt, A., Brachvogel, P. and Hausamen, J.E. (2004) Adenoid Cystic Carcinoma of the Head and Neck: A 20 Years Experience. International Journal of Oral and Maxillofacial Surgery, 33, 25-31. https://doi.org/10.1054/ijom.2003.0448

[18] Prasad, A.R., Savera, A.T. and Gown, A.M. (1999) The Myoepithelial Immunophenotype in 135 Benign and Malignant Salivary Gland Tumors Other than Pleomorphic Adenoma. Archives of Pathology \& Laboratory Medicine, 123, 801-806.

[19] Castler, J.D. and Conley, J.J. (1992) Surgical Management of Adenoid Cystic Carcinoma in the Parotid Gland. Otolaryngology_Head and Neck Surgery, 106, 332-338. https://doi.org/10.1177/019459989210600403

[20] Prokopakis, E.P., Snyderman, C.H., Hanna, E.Y., Carrau, R.L., Johnson, J.T. and D’Amico, F. (1999) Risk Factors for Local Recurrence of Adenoid Cystic Carcinoma: The Role of Postoperative Radiation Therapy. American Journal of Otolaryngology, 20, 281-286. https://doi.org/10.1016/S0196-0709(99)90028-5 